\title{
CARDIAC OUTPUT RESPONSE TO ALTERED ACID-BASE STATUS DURING DIETHYL ETHER ANAESTHESIA
}

\author{
Joseph O. Sodipo, Do-Chil Lee, and LuCien E. MorRis
}

CARDIOVASCULAR EFFECTS of anaesthetic agents are an important consideration for the anaesthetist in the management of any patient and particularly so in patients with pre-existing myocardial disease with some degree of hypovolaemia. Many patients have been lost from sudden or gradual cardiovascular effects of each agent and the potential consequences of each technique. It is important also to know the effect of anaesthetic agents and techniques in promoting changes in acid-base status, since this in itself is most likely to have a marked and deleterious effect on the cardiovascular system.

Reports of the effects of various anaesthetic agents upon the cardiac output have been conflicting. This is understandable in view of the large number of factors which relate to, or in some way modify, the cardiac output. Not the least of these are the often unrecognised effects of alterations in acid-base balance occurring during anaesthesia. It has been a common experience of research workers that the cardiac output of dogs under apparent steady state pentobarbitone frequently shows great variation in cardiac output between repeated determinations on the same animal. Some difficulties in correlating the effects of specific anaesthetic drugs are the result of marked acid-base changes. With several anaesthetic agents it has now been shown experimentally that with $\mathrm{Pa}_{\mathrm{Co}_{2}}$ held steady at $40 \pm 3$ torr, cardiac output, stroke volume and heart rate consistently decline with decreasing $\mathrm{pH}^{1-6}$ When compared at MAC-1 levels of anaesthesia these results are surprisingly similar between anaesthetic agents, but there are demonstrable differences in the slope of depression..$^{1-6}$

In clinical anaesthesia, diethyl ether was long considered the safest general anaesthetic, probably because of minimal effects upon the ordinary objective clinical measurements of cardio-vascular performance. This seems inconsistent with the observation that moderately severe metabolic acidosis frequently develops during an ether anaesthetic of long duration. Consequently it was decided to study the cardiovascular effects of deliberately induced acid-base abnormalities in dogs anaesthetized with diethyl ether (MAC-1).

This work was carried out at the University of Toronto, Anaesthesia Research Laboratory at St. Michael's Hospital, Toronto.

Present addresses of the authors are: Joseph O. Sodipo, F.F.A.R.C.S., F.W.C.S., Associate Professor of Anaesthesiology, College of Medicine, University of Lagos, P.M.B. 12003, Lagos, Nigeria. Do-Chil Lee, M.D., Associate Professor of Anaesthesia Research, Medical College of Ohio at Toledo. Lucien E. Morris, M.D., Professor and Chairman, Department of Anaesthesia, Medical College of Ohio at Toledo, P.O. Box 6190, Toledo, Ohio 43614, U.S.A.

Part of this paper was presented at the Fifth World Congress of Anaesthesiologists in Kyoto, Japan (1972). 


\section{METHODS}

Anaesthesia was induced with thiopentone in 25 mongrel male dogs, with chronically implanted electromagnetic flow probes (EMF) on the ascending aorta, and the trachea was intubated. Anaesthesia was maintained with a constant expired concentration of 3 per cent diethyl ether (MAC-1) ${ }^{7}$ using a copper kettle vaporizer. Ventilation was achieved with a volume-controlled animal ventilator during succinyl-choline apnoea. Expired carbon dioxide was monitored with an infra-red analyzer to facilitate maintenance of ventilation appropriate to an arterial carbon dioxide tension of $40 \pm 3$ torr.

The femoral artery was cannulated and blood pressure was recorded using a resistance transducer. Arterial cannulation allowed blood sampling for determinations of arterial $\mathrm{pH}, \mathrm{P}_{\mathrm{CO}_{2}}, \mathrm{P}_{\mathrm{O}_{2}}$ and electrolytes. The arterial blood levels of diethy] ether were determined by gas chromatography. A central venous pressure catheter was in situ for measurement and intravenous infusion. Oesophageal temperature was measured by a telethermometer and maintained at $37^{\circ} \pm 1^{\circ} \mathrm{C}$. Blood gas analyses were corrected to animal temperature using appropriate correction factors. ${ }^{8-9}$

The electromagnetic flow probe was connected to a Beckman recording dynograph and a flow wave was obtained. An integral of this wave form was triggered by the electrocardiogram QRS to obtain a trace of stroke volume for each heart beat, according to the method of Scher, et al. ${ }^{10}$ Comparison of this method for determination of cardiac output with the dye-dilution technique has shown a good correlation coefficient of $0.9 .^{11}$

Four acid-base states were crented and studied; metabolic acidaemia and alkalaemia, respiratory acidaemia and alkalaemia. Metabolic acidaemia data were obtained by two methods:

(a) exogenously produced by the infusion of $20 \mathrm{ml}$ of 0.6 Molar hydrochloric acid.

(b) by carefully induced hypoxia through reduction of the inspired oxygen concentration $\left(\mathrm{Fi}_{\mathrm{O}_{2}}\right)$ to 0.1 or less.

Measurements of cardiac output and arterial blood gas determinations were made approximately 25 and 35 minutes after acid infusion or after 25 minutes recovery from hypoxia. Metabolic alkalaemia was produced by the intravenous infusion of $20 \mathrm{ml}$ of 5 per cent sodium bicarbonate. Again cardiac output measurement and blood gas determinations were made approximately 25 and 40 minutes after alkali infusion.

Respiratory acidaemia was studied during alterations of inspired concentrations of carbon dioxide at steps of $0,5,10,15,20,15,10,5$, and 0 per cent. Cardiac output measurements and blood gas determinations were obtained 20 minutes after each change in per cent carbon dioxide. Respiratory alkalaemia data were obtained using constant volume hyperventilation and incremental removal of mechanical dead space. Cardiac output determinations and blood gas determinations were obtained 20 minutes after each decrease in mechanical dead space.

A laboratory animal was subjected to one acid-base state on one laboratory day. Occasionally, an animal was re-subjected to the same acid-base state to determine 
whether similar results would be obtained. Where possible, laboratory animals were subjected to other acid-base states after a suitable recovery period from earlier experiments. These animals were only used when baseline values for cardiac output and blood gas determination were shown to be similar to previous acid-base studies.

\section{Results}

(1) Repetition of infusions of $0.6 \mathrm{M}$ hydrochloric acid or episodes of hypoxia produced a series of cardiac output values at varied $\mathrm{pH}$ levels with $\mathrm{Pa}_{\mathrm{CO}_{2}}$ held constant at $40 \pm 3$ torr. The data from these experiments show that there was considerable variability between individual dogs. In general, however, cardiac output at first declined only slightly with decreasing $\mathrm{pH}$ (Figures 1 and 2), but a more marked fall became evident in severe metabolic acidaemia. In order to make comparisons between experiments the cardiac output in litres per minute was converted to per cent change in cardiac output and plotted against $\mathrm{pH}$. The mean slope from the individual regression lines for four exogenous metabolic acidaemia experiments is $+1.301 \pm$ a standard error (SE) 0.316 (Figure 1). The mean slope from regression lines of two hypoxia experiments is +3.62 S.E. \pm 0.210 (Figure 2).

(2) Respiratory acidaemia data from six experiments shows that cardiac output usually increased slightly with each increase in concentration of inspired carbon dioxide, but again there was considerable variation between individual

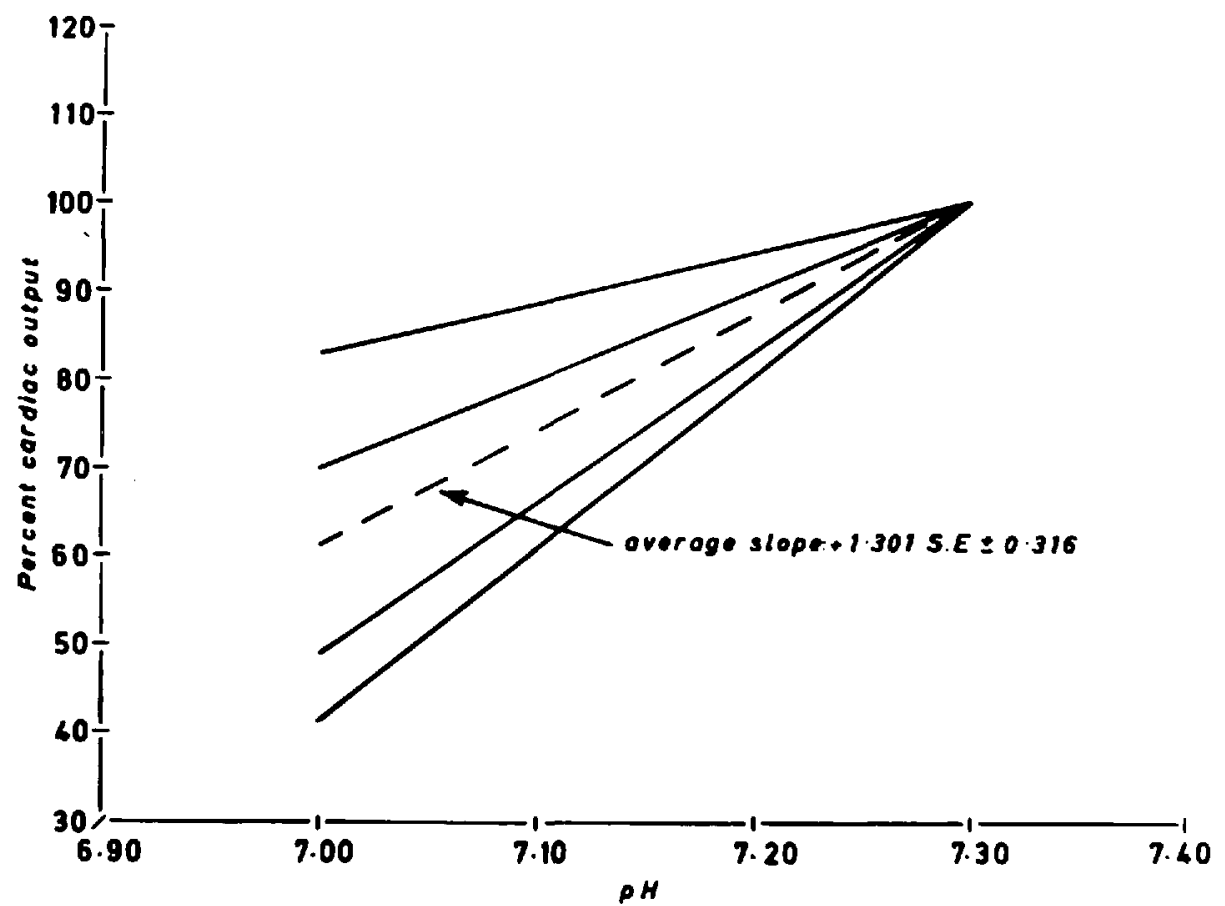

Figure 1. Data from four $\mathrm{HCl}$ infusion metabolic acidaemia studies converted to a percentage to show the linear relationship of $\mathrm{pH}$ to per cent cardiac output. 


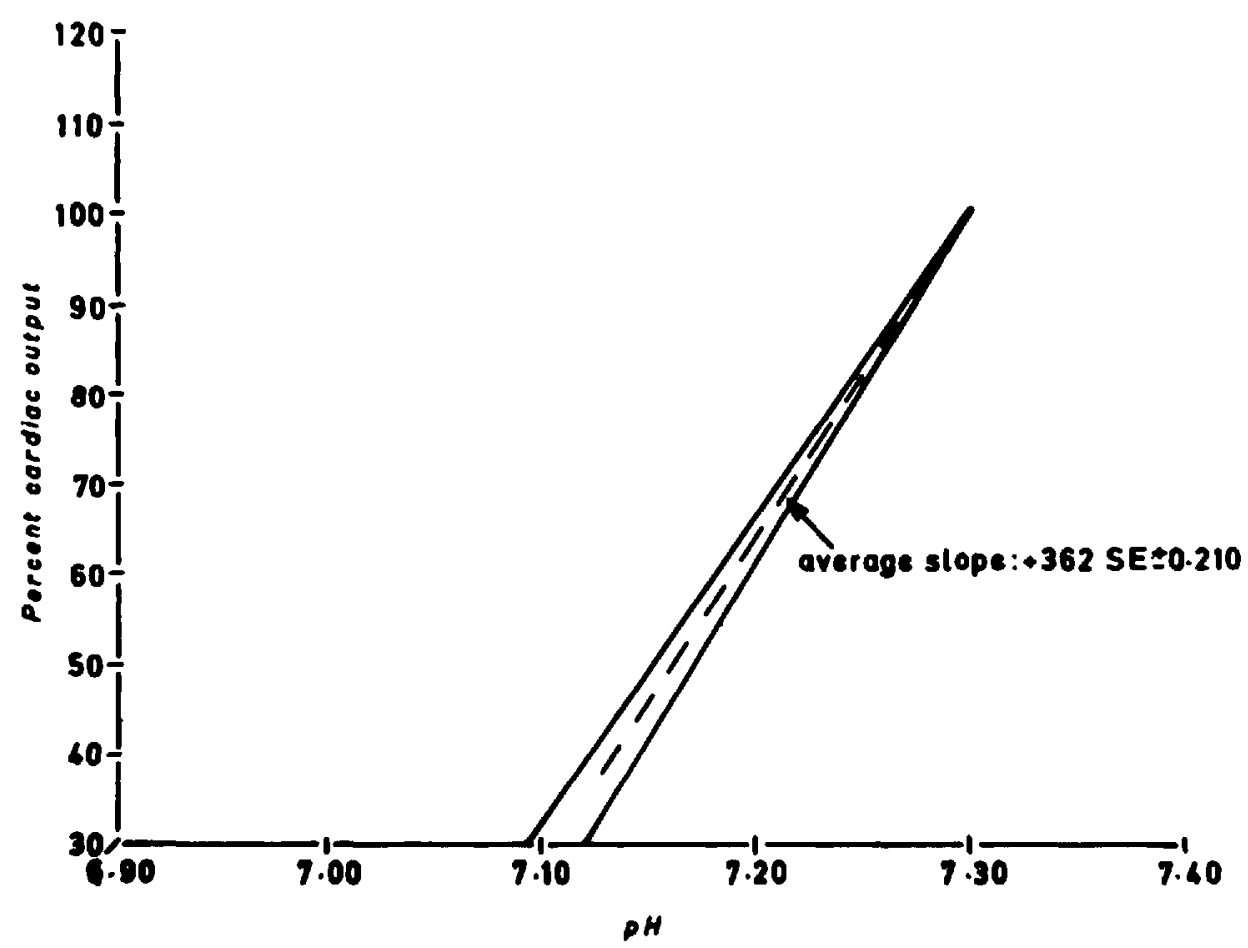

Figure 2. Data from two induced hypoxia metabolic acidaemia experiments converted to a percentage to show the linear relationship of $\mathrm{pH}$ to per cent cardiac output.

dogs and one of these responded by an actual decrease in cardiac output. When this data was converted to percentage change in cardiac output the mean slopes from individual regression lines obtained in these six experiments is -0.430 S.E. \pm 0.231 (Figure 3 ).

(3) Respiratory alkalaemia data obtained in three experiments during which cardiac output was obtained to decrease with hypocapnia. The average slope of individual regression lines of the decline of per cent change in cardiac output plotted against $\mathrm{pH}$ for these three experiments is -1.235 S.E. \pm 0.405 (Figure 4).

The duration of the respiratory studies were ordinarily three hours or more after which cardiac output and other cardiovascular parameters had ordinarily returned to levels closely similar to original base line. Consequently, these serve as a sort of control for the metabolic acidosis series to rule out the possible criticism that duration of anaesthesia per se might have caused the observed decrease in stroke volume and cardiac output rather than being the effect of the induced changes in $\mathrm{pH}$.

(4) Metabolic alkalaemia data were obtained in five experiments. Alkalaemia was induced by infusion of 5 per cent sodium bicarbonate during which cardiac output was again observed to decline with variable results. The average slope of individual regression lines of the decline per cent change in cardiac output plotted against $\mathrm{pH}$ for these five experiments is -2.047 S.E. \pm 0.262 (Figure 5). 


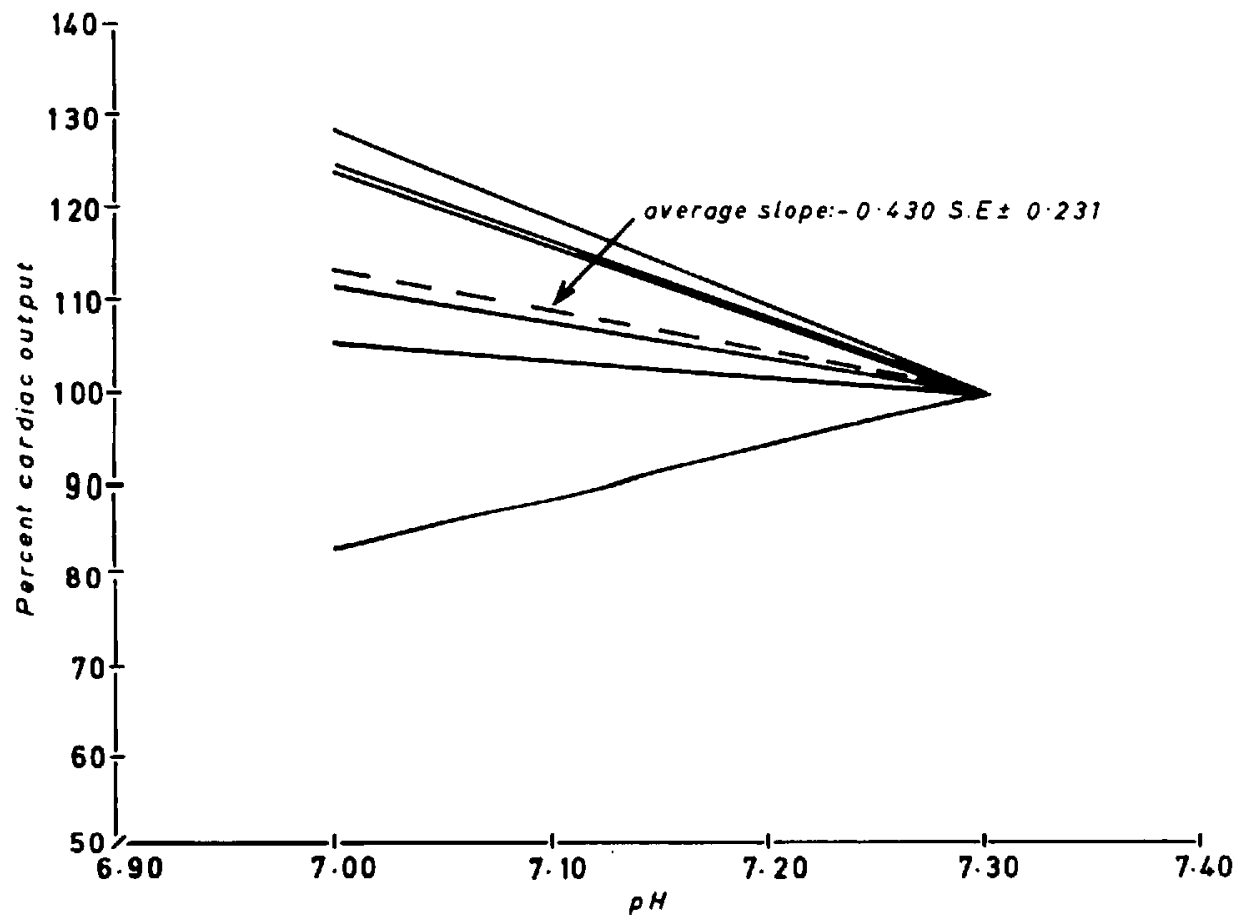

Figune 3. Respiratory acidaemia data from six studies converted to a percentage to show the linear relationship of $\mathrm{pH}$ to per cent cardiac output.

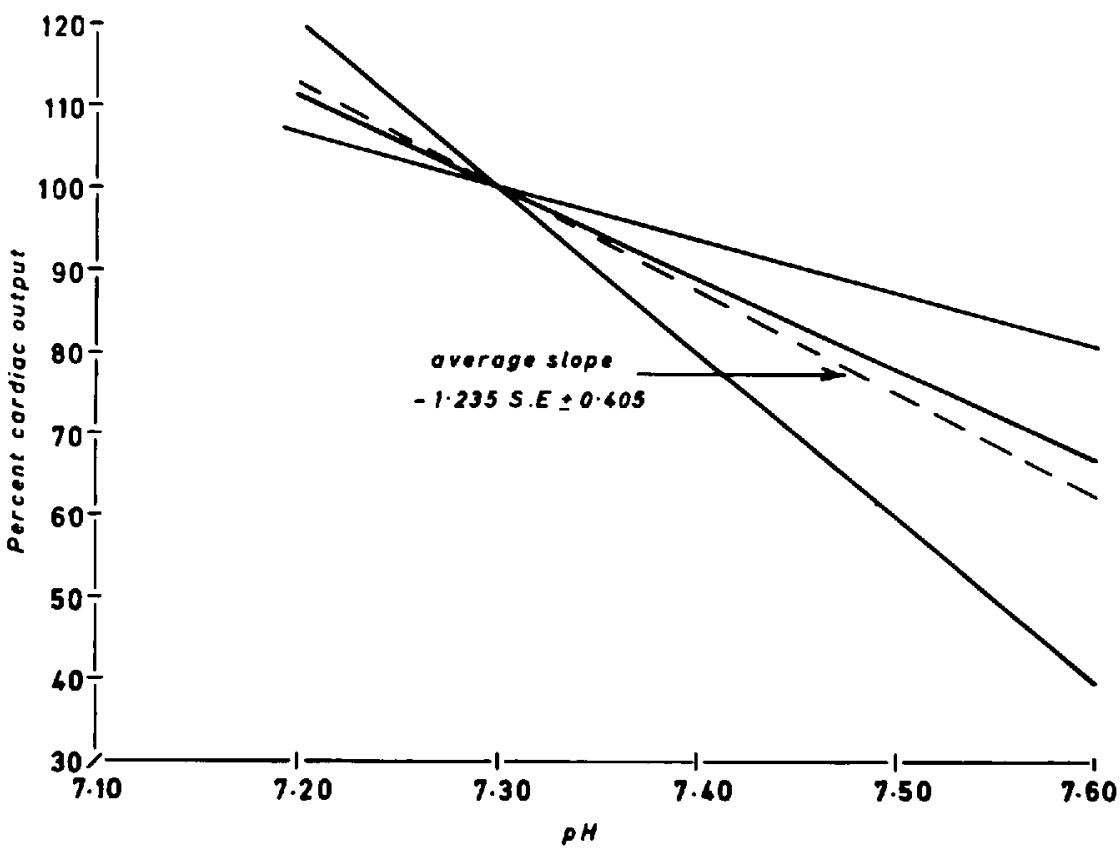

Figure 4. Data from four respiratory alkalaemia studies converted to a percentage to show the linear relationship of $\mathrm{pH}$ to per cent cardiac output. 


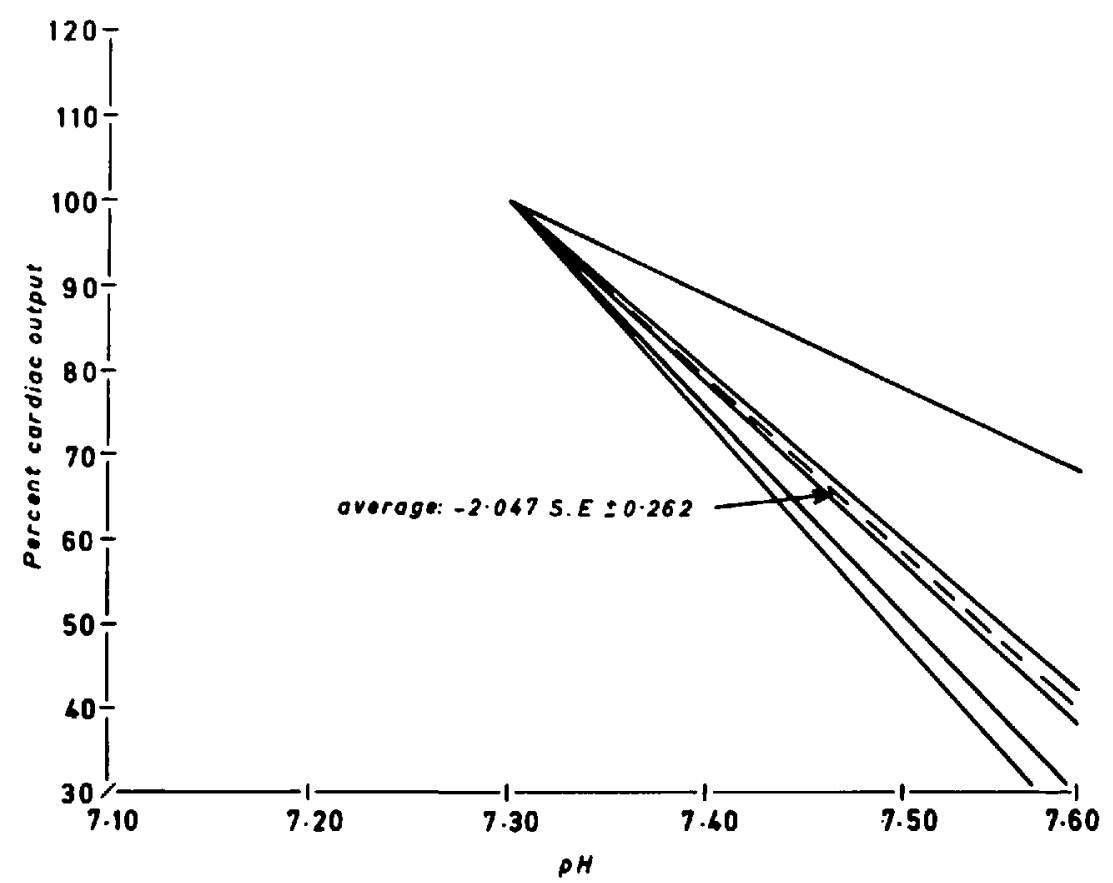

FIGURE 5. Metabolic alkalaemia data from five studies converted to a percentage to show the linear relationship of $\mathrm{pH}$ to per cent cardiac output.

\section{Discussion}

In contrast to the studies with phenobarbitone, ${ }^{1}$ halothane, ${ }^{2-4}$ fluroxene ${ }^{5}$ and methoxyflurane, ${ }^{6}$ in which the decline in cardiac output was in direct proportion to the decrease in $\mathrm{pH}$, whether produced by acid infusion or as a metabolic result of hypoxia, during diethyl ether anaesthesia there was frequently little fall in cardiac output with decreasing $\mathrm{pH}$ until severe metabolic acidosis was produced.

Similarly with increases in the concentration of inspired carbon dioxide the observed moderate increases in cardiac output were usually less marked than had been found with other anaesthetic agents. ${ }^{1-6}$

Thus it seems that in some way diethyl ether anaesthesia at first protects against the adverse effects of induced acid base abnormalities as seen with other anaesthetic agents. It appears that this may be related to inherent characteristic changes in perfusion, variaion in autonomic response, catecholamine release by ether or some other factors. This tends to confirm the clinical impression of cardiovascular stability usually exhibited by diethyl ether anaesthesia, but leaves the reason unexplained.

\section{SUMMARY}

The effects of acid-base changes on cardiac output during diethyl ether anaesthesia were studied in 25 mongrel dogs prepared by surgically implanting a plastic encased non-ferrous core electromagnetic probe on the ascending aorta. The findings are:

(1) Metabolic acidaemia produced only slight decrease in cardiac output but a more marked fall became evident with decreasing $\mathrm{pH}$. 
(2) Respiratory acidaemia led to a slight rise in cardiac output.

(3) Respiratory alkalaemia decreased cardiac output.

(4) Metabolic alkalaemia also produced a decline in cardiac output.

\section{RÉSUMÉ}

Les auteurs ont étudié les effets sur le débit cardiaque des modifications de l'équilibre acide-base au cours de l'anesthésie à l'éther chez 25 chiens. On avait préalablement procédé chez ces chiens à une implantation chirurgicale d'une sonde électromagnétique à noyau non-ferreux, placé sur l'aorte ascendante.

Les résultats obtenus ont été :

1. L'acidémie métabolique ne produit qu'une légère diminution du débit cardiaque, mais une baisse plus importante se manifeste avec un $\mathrm{pH}$ plus abaissé.

2. L'acidémie respiratoire provoque un légère augmentation du débit cardiaque.

3. L'alcalémie respiratoire abaisse le débit cardiaque.

4. L'alcalémie métabolique produit également une diminution du débit cardiaque.

\section{ACKNOWLEDGMENTS}

The authors wish to thank Professor R.A. Gordon who sponsored the trip of one of us (J.O. Sodipo) to Canada; Dr. V.M. Jones for chromatograph estimations of blood diethyl ether; J.C. Kay for aid with the statistics; Y. Gaiger for technical assistance and Mrs. Kehinde Molokwu for secretarial assistance.

This study was supported by a grant from the Medical Research Council of Canada (MA 3376).

\section{REFERENCES}

1. Carson, S.A.A., Chorley, G.E., Hamilton, F.N., Minzel, J.C., Schlobolhm, R.M., Monris, L.E., \& LEE, Do-ChIL. Variation in cardiac output with acid-base changes in the anaesthetized dog. J. Appl. Physiol. 20: 5, 948-953 (1965).

2. Tomlin, P.J., Schlobohm, R.M., Carson, S.A.A., \& Morris, L.E. Variation in cardiac output with acid-base changes in the halothane anaesthetized dog. Abstract: Brit. J. Anaesth. 38: 660 (1966).

3. Schlobohn, R.M., Hamilton, F.N., Tomlin, P.J., \& Morris, L.E. Halothane, peripheral vascular resistance and respiratory acidosis.

4. SodrPo, J.O. Effects of propranolol on cardiovascular response to hypercapnia with halothane anaesthesia. Fed. Proc. 29: 476 (1970).

5. Stoyka, W.W., Murphy, P.V, \& Morhis, L.E. Cardiac output variations with acid-base change during trifluoro-ethyl-vinyl-ether (Fluoromar). Fed. Proc. 29: 525 (1970).

6. Stoyka, W.W. Cardiac output changes with altered acid-base status during methoxyflurane anaesthesia. Can. Anaesth. Soc. J. 19: 119-128 (1972).

7. Edgen, E.I., Brandstater, B., Samman, L.J., Regan, M.J., Severinghaus, J.W., \& Munson, E.S. Equipotent alveolar concentrations of methoxyflurane, halothane, diethyl-ether, fluroxene, cyclopropane, xenon and nitrous oxide in the dog. Anesthesiology 26: 771-777 (1965).

8. Rosenthal, T.B. The effects of temperature on the $\mathrm{pH}$ of blood and plasma in vitro. J. Biol. Chem. 173: 25-30 (1948).

9. Bradley, A.F., Stupfel, M., \& Severivghaus, J.W. Effect of temperature on $\mathrm{P}_{\mathrm{CO}_{2}}$ and $\mathrm{P}_{\mathrm{O}_{2}}$ of blood in vitro. J. Appl. Physiol. 9: 201-204 (1956).

10. Scher, A.M., Zepeda, J., \& Brown, O.F. Square wave electromagnetic flometer employing commercially available recorder. J. Appl. Physiol. 22: 362-364 (1967).

11. Hamilton, F.N., Minzel, J.C., \& SснцовонM, R.M. Measurement of cardiac output by two methods in dogs. J. Appl. Physiol. 22: 2, 362-364 (1967). 